\title{
GLUL rs10911021 polymorphism and risk of coronary artery disease among Egyptian individuals
}

\author{
Rasha Nazih Yousef ${ }^{1 *}$ (D), Solaf Ahmed Kamel', Nehal Salah Hasan', Mona Awad', Hesham Gamal', \\ Nevine Ibrahim Musa ${ }^{2}$ and Mona Hamed Farag ${ }^{1}$
}

\begin{abstract}
Background: Genome-wide association studies have identified novel genes related to coronary artery disease (CAD). These studies have been replicated in distinct ethnic populations, returning inconsistent results. Our work aimed to study the frequency of $C$ and T alleles of GLUL polymorphism genetic variant rs10911021 among Egyptians with coronary artery disease in comparison to apparently healthy subjects. Our study included 420 patients with CAD (180 CAD without T2DM, 240 CAD with T2DM patients) and 200 control subjects. All subjects were genotyped for rs10911021 by real-time polymerase chain reaction.

Results: For rs 10911021 , the frequency of $(C / T+T / T)$ genotypes was significantly higher in CAD patients with and without T2DM than in controls $(55(45+10) \%$ vs. $22(19+3) \% ; p<0.001)$ and $(50(45+5) \%$ vs. $22(19+3) \% ; p<0.001$ respectively). The genotype C/C was the most frequent among the controls (78\%). The presence of GLUL polymorphism was associated with 4.4-fold increased risk to develop $C A D$ in diabetic patients $(O R=4.4,95 \% \mathrm{Cl}=(2.2-8.7) ; p<0.001)$ and was associated with 2.3-fold increased risk to develop $\mathrm{CAD}(\mathrm{OR}=2.3,95 \% \mathrm{Cl}=(1.1-4.6) ; p=0.0213)$.
\end{abstract}

Conclusion: In conclusion, among Egyptians, the GLUL polymorphism susceptibility variant rs10911021 is associated with $C A D$, with and without T2DM.

Keywords: Coronary artery disease, Single-nucleotide polymorphism, GLUL, Type 2 diabetes mellitus

\section{Background}

Coronary artery disease $(\mathrm{CAD})$ is considered one of the major causes of mortality and disability in developed countries; it is responsible for about one third or even more of all deaths among individuals over the age of 35 . Approximately one half of all middle-aged males and one third of middle-aged females in the USA may develop some manifestation of CAD (Benjamin et al. 2018).

For many years, the role of genetic elements in modifying the susceptibility to CAD has been recognized. Identifying predictors of cardiovascular mortality in high-risk populations may improve the clinical management and help in risk stratification (Cox et al. 2014). Genetic association

\footnotetext{
* Correspondence: rashanazzih@yahoo.com

1 Department of Clinical and Chemical Pathology, National Research Centre (NRC), Cairo 12622, Egypt

Full list of author information is available at the end of the article
}

studies have recognized about 60 genetic variants with strong links to the risk of CAD (Khera and Kathiresa 2017).

Cardiovascular risk factors, mainly diabetes, hypertension, dyslipidemia, smoking, and sedentary lifestyles, are responsible for the high incidence of CAD (Almahmeed et al. 2012).

Cardiovascular disease is considered the main leading causes of mortality and morbidity among diabetic patients (Einarson et al. 2018).

Previous studies detect significant heterogeneity in genetic effects between CAD participants with and without diabetes. This could hypothesize that other undiscovered loci may present and influence the risk of CAD in the presence of diabetes (Qi et al. 2011).

Detecting such genes might be the target of new interferences trying to prevent or treat $\mathrm{CAD}$ among patients with diabetes. rs10911021, a single-nucleotide polymorphism upstream of the glutamate-ammonia ligase gene (GLUL), 
was identified as being mainly related to CAD in patients with type 2 diabetes. It was found that rs10911021 was not associated with the risk of developing T2DM, glucose intolerance, or insulin resistance (Qi et al. 2013).

In this study, we aimed to study the frequency of $\mathrm{C}$ and $\mathrm{T}$ alleles of GLUL polymorphism genetic variant rs10911021 among 420 Egyptians with coronary artery disease in comparison to 200 apparently healthy subjects.

\section{Methods}

\section{Subjects}

Informed consent was obtained from all subjects, and the study protocol was approved by the Ethics Committee of the National Research Centre.

Our study included 420 subjects recruited from outpatients' clinic of the National Research Centre and Coronary Care Unit (CCU) of Ain Shams Hospital, Cairo, Egypt. All participants answered a questionnaire used for collecting socioeconomic data, as well as a family history of CVD, diabetes, and other diseases. Anthropometric measurements were performed: weight $(\mathrm{kg})$, height $(\mathrm{cm})$, and waist circumference $(\mathrm{cm})$. Body mass index (BMI) $\left(\mathrm{kg} / \mathrm{m}^{2}\right)$ was calculated according to the standard formula $\mathrm{BMI}=$ weight $(\mathrm{kg}) /[\text { height }(\mathrm{m})]^{2}$. According to the American Heart Association/National Heart, Lung, and Blood Institute Scientific Statement (AHA/NHLBI), hypertension was defined as systolic blood pressure (SBP) $\geq 130 \mathrm{mmHg}$, diastolic blood pressure $(\mathrm{DBP}) \geq 85 \mathrm{mmHg}$, or under antihypertensive drugs and was measured with a mercury column sphygmomanometer (American Diagnostic Inc., New York) after the patients had rested and were seated for at least 5 min. According to the American Diabetes Association (ADA), DM is diagnosed when fasting blood glucose level $\geq 126 \mathrm{mg} / \mathrm{dl}$ after $8 \mathrm{~h}$ fasting, 2-h plasma glucose level $\geq 200 \mathrm{mg} / \mathrm{dL}$ during a 75 -g oral glucose tolerance test, or a random plasma glucose $\geq 200 \mathrm{mg} / \mathrm{dL}$ in a patient with classic symptoms of hyperglycemia (i.e., polydipsia, polyuria, weight loss, polyphagia). Our subjects were classified into:

Normal healthy control group

Included 200 apparently healthy volunteers age matched with fasting blood glucose $(\mathrm{FBS})<100 \mathrm{mg} / \mathrm{dl}$. Exclusion criteria were hyperlipidemia, hypertension, CAD, diabetes mellitus, hepatic and renal diseases, endocrine disease, metabolic disorders, autoimmune diseases, and being under medication.

CAD patients

Four hundred twenty CAD patients are subdivided into:

- One hundred eighty patients with CAD as ischemic heart disease, but without diabetes mellitus

- Two hundred forty CAD patients with T2DM
CAD as ischemic heart disease was diagnosed based on typical chest pain lasting longer than $30 \mathrm{~min}$, characteristic electrocardiographic patterns of myocardial infarction as the presence of ST-segment changes or Q-waves on ECG, elevation of cardiac enzymes (creatine kinase), and troponin I or $\mathrm{T}$ in blood. Diabetic patients were recruited based on their medical record and fulfillment of the diagnostic criteria of ADA for T2DM that specify fasting plasma glucose (FPG) $\geq 126$ $\mathrm{mg} / \mathrm{dL}$ or $2-\mathrm{h}$ plasma glucose $(\mathrm{PPG}) \geq 200 \mathrm{mg} / \mathrm{dL}$ or random plasma glucose (random blood sugar) $(\mathrm{RBG}) \geq$ $200 \mathrm{mg} / \mathrm{dL}$. Exclusion criteria included other cardiac diseases including vacuities (inflammation of blood vessels), valvular disease, and congenital anomalies.

Other types of diabetes as type 1 diabetes mellitus, and maturity onset diabetes of the young, renal disease, hepatic disease, endocrine disease, and autoimmune diseases.

We summarized the clinical characteristics of the studied groups in Table 1.

\section{Methods \\ Lipid analysis and biochemical markers}

Venous blood samples were obtained from either fasting or non-fasting participants admitted to the Coronary Care Unit (CCU) of Ain Shams Hospital in order to facilitate obtaining data from each subject. Two EDTA tube blood samples were collected; one of them was stored at $-20^{\circ} \mathrm{C}$ till DNA extraction for genotyping and the other used for measuring glycated hemoglobin (HbA1c). Blood on the plain tubes was allowed to clot for $30 \mathrm{~min}$ and then centrifuged at $3000 \times g$ for $10 \mathrm{~min}$. Sera were stored at $-20^{\circ} \mathrm{C}$ till the time of analysis.

Measurement of serum levels of fasting, $2 \mathrm{~h}$ post prandial blood glucose, HbA1c, and lipid profile [total cholesterol, high-density lipoprotein (HDL) cholesterol (HDL-C, $\mathrm{mg} / \mathrm{dL})$, and triglycerides $(\mathrm{mg} / \mathrm{dL})$ ] was performed on automated clinical chemistry analyzer (OLYMPUS AU400). Low-density lipoprotein cholesterol (LDL-C) level was calculated using the Friedewald formula: LDL-C $=\mathrm{TC}-$ HDL-C - TG/5 mg/dl (Friedewald et al. 1972).

\section{Serum paraoxonase 1 (PON1), high-sensitive C-reactive protein (hsCRP), and insulin concentrations}

Serum PON1 was measured by ELISA (quantitative sandwich enzyme-linked immunosorbent assay technique) MyBioSource, Inc. P.O. Box 153308 San Diego, CA 92195-3308, USA. hsCRP and insulin concentrations were assayed on Roche Diagnostics clinical chemistry autoanalyzer e411 (Germany).

\section{Genotyping of GLUL polymorphism (rs10911021)}

DNA was extracted using QIAamp DNA Blood Mini Kits -50- Catalog no. 51104 supplied by QIAGEN. DNA integrity was determined by $1 \%$ agarose gel 
Table 1 Demographic and biochemical variables of the study populations

\begin{tabular}{llll}
\hline & CAD with T2DM, N=240 & CAD, N=180 & Controls, $N=200$ \\
& Mean \pm SEM & Mean \pm SEM & Mean \pm SEM \\
\hline Age & $49.53 \pm 0.8$ & $48.94 \pm 8.8$ & $41.9 \pm 1.0$ \\
Sex no. (\%) & & & \\
\multicolumn{1}{c}{ Female } & $110(45.8 \%)$ & $45(25 \%)$ & $92(46.0 \%)$ \\
\multicolumn{1}{c}{ Male } & $130(54.2 \%)$ & $135(75 \%)$ & $108(54.0 \%)$ \\
Height & $166.93 \pm 1.0$ & $169.83 \pm 0.7$ & $165.6 \pm 1.07$ \\
Weight & $90.51 \pm 1.2$ & $95.08 \pm 1.1$ & $74.12 \pm 1.3$ \\
Waist & $109.52 \pm 1.0$ & $102.48 \pm 1.2$ & $88.34 \pm 1.2$ \\
BMI & $32.58 \pm 0.4$ & $33.15 \pm 0.4$ & $27.26 \pm 0.5$ \\
SBP & $143.9 \pm 1.6$ & $148.45 \pm 1.6$ & $120.6 \pm 12.4$ \\
DBP & $88.4 \pm 1.4$ & $92.4 \pm 1.2$ & $80 \pm 10.1$ \\
FBS & $207.88 \pm 5.8$ & $93.13 \pm 2.1$ & $91.09 \pm 2.0$ \\
2HPP & $245.17 \pm 8.3$ & $100.6 \pm 1.9$ & $97.82 \pm 2.2$ \\
HbA1C & $8.34 \pm 0.15$ & $5.58 \pm 0.08$ & $5.15 \pm 0.06$ \\
Cholesterol & $207.9 \pm 5.2$ & $209.55 \pm 6.1$ & $163.78 \pm 3.3$ \\
TG & $192.26 \pm 7.4$ & $171.27 \pm 6.3$ & $102.51 \pm 3.4$ \\
HDL & $34.5 \pm 0.88$ & $33.18 \pm 0.9$ & $49.16 \pm 0.9$ \\
LDL & $133.45 \pm 5.0$ & $141.2 \pm 5.8$ & $92.96 \pm 3.5$ \\
hsCRP & $117.29 \pm 5.9$ & $120.38 \pm 4.6$ & $70.14 \pm 3.8$ \\
INS & $11.33 \pm 2.4$ & $13.99 \pm 1.6$ & $6.86 \pm 0.8$ \\
PON1 & $25.82 \pm 1.3$ & $25.87 \pm 0.7$ & $82.94 \pm 3.3$ \\
\hline CAD with & con & & \\
\hline
\end{tabular}

CAD with T2DM coronary artery diseases with type 2 diabetes mellitus, $C A D$ coronary artery diseases, $B M I$ body mass index, $S B P$ systolic blood pressure, $D B P$ diastolic blood pressure, FBS fasting blood sugar, $2 H P P 2 \mathrm{~h}$ post prandial, HbA1c hemoglobin A1C (glycated hemoglobin), TG triglyceride, HDL highdensity lipoprotein, $L D L$ low-density lipoprotein, $C R P C$-reactive protein, INS insulin, PON1 paraoxonase 1

electrophoresis, stained with ethidium bromide, and visualized through GEL documentation (E-Gel ${ }^{\circ}$ Imager System with UV Light Base, Thermo Scientific). DNA concentration was determined by a NanoDrop 2000 Spectrophotometer (Thermo Scientific). GLUL polymorphism (rs10911021) was detected by real-time polymerase chain reactions (PCR) using the Quantistudio 12 Flex real-time PCR system (Applied Biosystems, CA 94404, USA). GLUL polymorphism (rs10911021) (Applied BiosystemsID) allele discrimination was performed using the $\operatorname{TaqMan}^{\circ}$ genotyping protocol (Applied Biosystems, Foster City, CA, USA). PCR reactions were set up in $20-\mu \mathrm{L}$ reaction volume including 20-30 ng DNA and $10 \mu \mathrm{L}$ TaqMan $^{\circ}$ Universal PCR Master Mix in 96-well PCR plates. For rs10911021, VIC/FAM probes were:

\section{AGAGCAATCTTCTGCAGCCTGTTCT[ [C/T]ATGT GAGGACCAGAAAAGTTTCCGC}

The PCR assay was carried out according to the manufacturer's instructions including one step of $10 \mathrm{~min}$ at $95^{\circ} \mathrm{C}$ followed by 40 cycles of DNA denaturation at $95^{\circ} \mathrm{C}$ for $15 \mathrm{~s}$ and annealing/extension at $60^{\circ} \mathrm{C}$ for $1 \mathrm{~min}$. Final products were analyzed by TaqMan Genotyper software.

\section{Statistical analysis}

The collected data and the clinical results have been statistically analyzed using IBM SPSS version 18.0 software (Statistical Package for Social Science). Quantitative data were expressed as mean values \pm standard deviation (SD). To ensure adequate statistical power, we included the allele frequency in the statistical study. Frequency of distributions was estimated for quantitative variables. Normally distributed data were compared using the ANOVA test for more than two groups while Kruskal-Wallis test was done for non-parametric data. The significance of differences between proportions was tested by the chi-square test $\left(x^{2}\right)$. Odds ratio and 95\% CI were calculated. Differences were considered significant with $p$ value $<0.05$. Allele and genotype differences between groups and deviations from Hardy-Weinberg equilibrium were tested by chi-square test. Univariate logistic regression analysis was used to test the association between diseases and gene polymorphism and presented as unadjusted odds ratios (OR) with confidence interval (95\% CI).

\section{Results}

Analysis of genotypes and allele distribution of GLUL polymorphism (rs10911021) in CAD with T2DM, CAD, and control subjects are shown in Table 2. There was a significant difference in the allele and genotype frequencies of GLUL polymorphism (rs10911021) among the coronary artery patients (either diabetic or not) and control groups. The genotype distributions of all groups were in Hardy-Weinberg equilibrium.

Table 2 Genotypes and allele frequency of GLUL polymorphism rs10911021 in CAD with and without T2DM and control groups

\begin{tabular}{|c|c|c|c|c|c|c|}
\hline & \multicolumn{3}{|c|}{ rs10911021 genotype } & \multirow[t]{2}{*}{$p$ value } & \multicolumn{2}{|c|}{$\begin{array}{l}\text { Allele } \\
\text { frequency }\end{array}$} \\
\hline & $\mathrm{CC}$ & $\mathrm{CT}$ & $\pi$ & & C & $\mathrm{T}$ \\
\hline CAD patients, $N=420$ & $\begin{array}{l}198 \\
(47 \%)\end{array}$ & $\begin{array}{l}189 \\
(45 \%)\end{array}$ & $\begin{array}{l}35 \\
(8 \%)\end{array}$ & $<0.001^{* *}$ & 585 & 255 \\
\hline $\begin{array}{l}\text { CAD without T2DM, } \\
N=180\end{array}$ & $\begin{array}{l}90 \\
(50 \%)\end{array}$ & $\begin{array}{l}81 \\
(45 \%)\end{array}$ & $\begin{array}{l}9 \\
(5 \%)\end{array}$ & $<0.001^{* *}$ & 261 & 99 \\
\hline $\begin{array}{l}\text { CAD and T2DM, } \\
N=240\end{array}$ & $\begin{array}{l}108 \\
(45 \%)\end{array}$ & $\begin{array}{l}108 \\
(45 \%)\end{array}$ & $\begin{array}{l}24 \\
(10 \%)\end{array}$ & $<0.001^{* *}$ & 324 & 156 \\
\hline Controls, $N=200$ & $\begin{array}{l}156 \\
(78 \%)\end{array}$ & $\begin{array}{l}38 \\
(19 \%)\end{array}$ & $\begin{array}{l}6 \\
(3 \%)\end{array}$ & & 350 & 50 \\
\hline
\end{tabular}

**The mean difference is highly significant at the 0.01 level (two-tailed) 
Table 3 Association between allele of the GLUL polymorphism rs10911021 and risk of CAD in T2DM patients

\begin{tabular}{llllll}
\hline & T (\%) & $\begin{array}{l}C \\
(\%)\end{array}$ & $\begin{array}{l}\text { Odds ratio } \\
(\mathrm{OR})\end{array}$ & $\begin{array}{l}\text { Confidence } \\
\text { interval }(\mathrm{Cl})\end{array}$ & $\begin{array}{l}x^{2} \\
(p \text { value })\end{array}$ \\
\hline $\begin{array}{l}\text { CAD and D.M, } \\
N=240\end{array}$ & 39 & 61 & 4.4 & $2.2-8.7$ & $p<0.001^{* *}$ \\
CAD, N=180 & 24.75 & 75.25 & 2.3 & $1.1-4.6$ & $p=0.0213$ \\
\hline
\end{tabular}

**The mean difference is highly significant at the 0.01 level (two-tailed)

MLR (multivariate logistic regression) evaluation after adjustment for other determined risk elements, age, BMI, and male gender, revealed that GLUL gene (rs10911021) was an independent risk factor of CAD in patients with or without T2DM. Regarding other covariates, age, BMI, and smoking status, they were independent risk factors for CAD risk in patients with T2DM or even without T2DM as shown in Table 3.

CAD (whether with T2DM or not) carrying the mutant allele (T) had higher BMI, waist, SBP, DBP, cholesterol, and LDL than those carrying the wild-type allele (C). HDL and PON1 were elevated in patients with CAD and T2DM carrying (T) allele in comparison to those carrying the wild-type allele $(\mathrm{C})$ as shown in Table 4.

\section{Discussion}

The risk of CAD which is the major cause of mortality in the world is determined by both genetic and non-genetic factors. The genetic determinants of CAD among type 2 diabetic patients are considered as risk factors for increased deaths among those subjects, and it has been strongly associated with SNP rs10911021 at the GLUL locus (Smith et al. 2010).

In risk allele carriers, the expression of GLUL gene that encodes glutamate-ammonia ligase and catalyzes the transformation of glutamic acid and ammonia into glutamine is decreased (Carobbio et al. 2004).

Many studies show that glutamine/glutamic acid metabolism is related to insulin secretion and glucose metabolism regulation. Glutamine increases both insulin secretion and mitochondrial metabolism in pancreatic islets (Beaney et al. 2016).

Our study tried to investigate the relationship between the GLUL polymorphism rs10911021 and the occurrence of coronary artery disease in the Egyptian population with or without T2DM. We found that this genetic variant was associated with CAD patients with and without type 2 diabetes. This goes hand in hand with a previous study which reported that rs10911021 polymorphism at the GLUL locus has been related to higher risk of coronary artery

Table 4 GLUL polymorphism rs10911021 and characteristics of subjects among the studied groups

\begin{tabular}{|c|c|c|c|c|c|c|}
\hline & \multicolumn{3}{|c|}{ CAD with T2DM $(N=240)$} & \multicolumn{3}{|l|}{ CAD $(N=180)$} \\
\hline & $\mathrm{T}(\%)$ & C (\%) & $p$ value & $\mathrm{T}(\%)$ & C (\%) & $p$ value \\
\hline Height (cm) & $164.9 \pm 9.9$ & $167.9 \pm 10$ & $0.047^{*}$ & $168.24 \pm 7.5$ & $170.4 \pm 7.4$ & 0.064 \\
\hline Weight (kg) & $91.49 \pm 10.4$ & $90.04 \pm 12.6$ & 0.42 & $99.89 \pm 14$ & $93.26 \pm 9$ & $0.002^{* *}$ \\
\hline Waist (cm) & $113.38 \pm 9.6$ & $107.66 \pm 11$ & $<0.001^{* *}$ & $107.82 \pm 12$ & $100.5 \pm 11.3$ & $<0.001^{*}$ \\
\hline $\mathrm{BMI}\left(\mathrm{kg} / \mathrm{m}^{2}\right)$ & $33.7579 \pm 4$ & $32.0069 \pm 4$ & $0.004^{* *}$ & $35.4 \pm 5.4$ & $32.3 \pm 4.2$ & $<0.001^{*}$ \\
\hline $\mathrm{SBP}(\mathrm{mmHg})$ & $151.08 \pm 18$ & $140.44 \pm 15$ & $<0.001^{* *}$ & $155 \pm 18$ & $145.97 \pm 15$ & $0.001^{* *}$ \\
\hline $\mathrm{DBP}(\mathrm{mmHg})$ & $94.85 \pm 15$ & $86.41 \pm 10$ & $<0.001^{* *}$ & $97.45 \pm 15$ & $90.48 \pm 11$ & $0.002^{* *}$ \\
\hline $\mathrm{FBS}(\mathrm{mg} / \mathrm{dL})$ & $202.02 \pm 49$ & $210.70 \pm 62$ & 0.323 & $94.04 \pm 21$ & $92.8 \pm 21.5$ & 0.711 \\
\hline $2 \mathrm{HPP}(\mathrm{mg} / \mathrm{dL})$ & $236.308 \pm 70$ & $249.437 \pm 88$ & 0.258 & $101.63 \pm 20$ & $100 \pm 19.3$ & 0.646 \\
\hline $\mathrm{HbA1c} \%$ & $8.3077 \pm 1.5$ & $8.3511 \pm 1.5$ & 0.85 & $5.761 \pm 0.8$ & $5.6 \pm 0.74$ & 0.055 \\
\hline $\mathrm{CHOL}(\mathrm{mg} / \mathrm{dL})$ & $220.462 \pm 49$ & $201.852 \pm 52$ & $0.017^{*}$ & $227.4 \pm 65$ & $202.78 \pm 58$ & $0.01^{*}$ \\
\hline $\mathrm{TG}(\mathrm{mg} / \mathrm{dL})$ & $184.015 \pm 35$ & $196.230 \pm 87$ & 0.161 & $183.61 \pm 61$ & $166.58 \pm 64$ & 0.091 \\
\hline $\mathrm{HDL}(\mathrm{mg} / \mathrm{dL})$ & $31.677 \pm 7.5$ & $35.859 \pm 9.0$ & $0.002^{* *}$ & $33.14 \pm 9.5$ & $33.19 \pm 9.2$ & 0.974 \\
\hline $\mathrm{LDL}(\mathrm{mg} / \mathrm{dL})$ & $152 \pm 51.5$ & $124.519 \pm 47$ & $<0.001^{* *}$ & $157.07 \pm 61$ & $135.17 \pm 56$ & $0.017^{*}$ \\
\hline CRP (mg/L) & $124.7 \pm 55$ & $113.7 \pm 61$ & 0.221 & $129.82 \pm 42$ & $116.8 \pm 47$ & 0.076 \\
\hline INS (mIU/L) & $10.8 \pm 28$ & $11.58 \pm 23.0$ & 0.828 & $12.18 \pm 16$ & $14.6 \pm 16.7$ & 0.34 \\
\hline PON1 (mlU/mL) & $22.75 \pm 7.2$ & $27.3 \pm 14$ & $0.021^{*}$ & $25.87 \pm 6$ & $25.8 \pm 8$ & 0.993 \\
\hline
\end{tabular}

CAD with T2DM CAD with type 2 diabetes mellitus, CAD coronary artery diseases, $B M I$ body mass index, SBP systolic blood pressure, DBP diastolic blood pressure, FBS fasting blood sugar, 2HPP $2 \mathrm{~h}$ post prandial, HbA1c hemoglobin A1c (glycated hemoglobin), CHOL cholesterol, $T G$ triglyceride, HDL high-density lipoprotein, LDL low-density lipoprotein, CRP c-reactive protein, INS insulin, PON1 paraoxonase 1

*The mean difference is significant at the 0.05 level (two-tailed)

**The mean difference is highly significant at the 0.01 level (two-tailed) 
disease in patients with T2DM (Smith et al. 2010). However, another study reported that no association between rs10911021 and CAD was seen in non-T2DM Look AHEAD individuals (The Look AHEAD Research Group 2016).

This study correlated the GLUL polymorphism rs10911021 with obesity and other factors for metabolic syndrome in cardiovascular patients whether having diabetes or not. Our study shows a significant association between GLUL polymorphisms and waist, BMI, SBP, DBP, cholesterol, LDL, HDL, and PON1.

We found that the GLUL polymorphism is associated with 4.4-fold increased risk to develop CAD among diabetic patients and was associated with 2.3 -fold increased risk to develop CAD; this is not in agreement with Qi et al. 2013 who found that the OR among non-diabetic CAD patients was not significantly different from 1, while it is significantly different from the OR in diabetic individuals with CAD.

\section{Conclusion}

We suggest GLUL rs10911021 as a predisposing locus for CAD in the region of the GLUL gene; however, more works are needed to better understand and recognize the biological mechanisms linking it to CAD in diabetes.

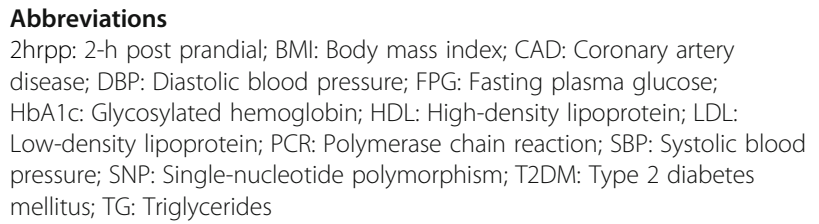

\section{Acknowledgements}

This work was supported by grant from National Research Centre, Egypt.

\section{Funding}

This work was supported by the National Research Centre.

\section{Availability of data and materials}

All data generated or analysed during this study are included in this published article (and its supplementary information files).

\section{Authors' contributions \\ NSH made the study design, supervised the project, collected and analyzed the data, and drafted the manuscript. SAK participated in the molecular genetic studies; participated in the sample collection, data collection, and analysis; and shared in writing the manuscript. RNY participated in the molecular genetic studies and biochemical investigations and helped in the writing and submission of the manuscript. MA participated in biochemical investigations and molecular genetic studies. HG participated in the molecular genetic studies and analyzed the data. MHF participated in the sample collection, data collection, and analysis. NIM collected the samples and data of cardiac patients. This manuscript was revised and approved by all authors.}

\section{Ethics approval and consent to participate}

Informed consent was obtained from all subjects and the study protocol was approved by the Ethics Committee of the National Research Centre.

\section{Competing interests}

The authors declare that they have no competing interests.

\section{Publisher's Note}

Springer Nature remains neutral with regard to jurisdictional claims in published maps and institutional affiliations.

\section{Author details}

'Department of Clinical and Chemical Pathology, National Research Centre (NRC), Cairo 12622, Egypt. ${ }^{2}$ Department of Internal Medicine, Ain Shams University, Cairo, Egypt.

Received: 30 June 2018 Accepted: 13 February 2019

Published online: 04 March 2019

\section{References}

Almahmeed W, Arnaout MS, Chettaoui R, Ibrahim M et al (2012) Coronary artery disease in Africa and the Middle East. Ther Clin Risk Manag 8:65-72

Beaney KE, Ward CE, Bappa DAS et al (2016) A 19-SNP coronary heart disease gene score profile in subjects with type 2 diabetes: the coronary heart disease risk in type 2 diabetes (CoRDia study) study baseline characteristics. Cardiovasc Diabetol 15:141

Benjamin EJ, Virani SS, Callaway CW et al (2018) Heart disease and stroke statistics-2018 update: a report from the American Heart Association. Circulation 137:e67

Carobbio S, Ishihara H, Fernandez-Pascual S et al (2004) Insulin secretion profiles are modified by overexpression of glutamate dehydrogenase in pancreatic islets. Diabetologia 47:266-276

Cox AJ, Hsu F-C, Ng MCY, Langefeld CD et al (2014) Genetic risk score associations with cardiovascular disease and mortality in the diabetes heart study. Diabetes Care 37:1157-1164

Einarson TR, Acs A, Ludwig C, Panton UH (2018) Prevalence of cardiovascular disease in type 2 diabetes: a systematic literature review of scientific evidence from across the world in 2007-2017. Cardiovasc Diabetol 17:83

Friedewald WT, Levy Rl, Fredrickson DS (1972) Estimation of the concentration of low-density lipoprotein cholesterol in plasma, without use of preparative ultracentrifuge. Clin Chem 18:499-402

Khera AV, Kathiresa S (2017) Genetics of coronary artery disease: discovery, biology and clinical translation. Nat Rev Genet 18(6):331-344

Qi L, Parast L, Cai T et al (2011) Genetic susceptibility to coronary heart disease in type 2 diabetes. J Am Coll Cardiol 58:2675-2682

Qi L, Qi Q, Prudente S et al (2013) Association between a genetic variant related to glutamic acid metabolism and coronary heart disease in individuals with type 2 diabetes. JAMA 310:821-828

Smith NL, Felix JF, Morrison AC et al (2010) Association of genome-wide variation with the risk of incident heart failure in adults of European and African ancestry: a prospective meta-analysis from the Cohorts for Heart and Aging Research in Genomic Epidemiology (CHARGE) consortium. Circ Cardiovasc Genet 3:256-266

The Look AHEAD Research Group (2016) Prospective association of GLUL rs 10911021 with cardiovascular morbidity and mortality among individuals with type 2 diabetes: the look AHEAD study. Diabetes 65:297-302

\section{Submit your manuscript to a SpringerOpen ${ }^{\circ}$ journal and benefit from:}

- Convenient online submission

- Rigorous peer review

- Open access: articles freely available online

High visibility within the field

- Retaining the copyright to your article

Submit your next manuscript at $\boldsymbol{\nabla}$ springeropen.com 